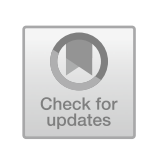

\title{
Higher Education for Women in Asia
}

\author{
Solveig Olson-Strom and Nirmala Rao
}

\section{INTRODUCTION}

The recent rapid growth in higher education around the world is undeniable. Worldwide enrolments have increased manifold in the past two or three decades, and a large part of this is due to women entering degree programs in multitudes. In terms of attendance rates, the gender gap in tertiary education has virtually disappeared in most places. In fact, women even outnumber men in higher education in many countries around the world, including developing and industrialized countries across all regions. In Asia especially, women's enrolment has accelerated in recent years as overall demand for higher education has accelerated. But do these encouraging numbers accurately reflect the bigger picture? By other measures, gender inequality in higher education remains a significant issue. Women continue to be overrepresented in certain fields and underrepresented in others (often those that are considered more prestigious or have higher earning potential). Their experiences at higher education institutions are vastly different from those of men in terms of campus climate and leadership opportunities. Employment outcomes also

S. Olson-Strom $(\bowtie) \cdot$ N. Rao

Asian University for Women, Chittagong, Bangladesh

e-mail: nirmala.rao@auw.edu.bd

(C) The Author(s) 2020

263

C. S. Sanger and N. W. Gleason (eds.),

Diversity and Inclusion in Global Higher Education, https://doi.org/10.1007/978-981-15-1628-3_10 
indicate persistent inequality. How do we interpret these seemingly contradictory developments? It is essential to understand the causes behind these trends in order to effectively tackle the ongoing challenges to gender equality in higher education.

Much of the literature surrounding gender and higher education has focused on North America (primarily the United States) and Western Europe. Yet Asia, though not homogeneous by any means, presents a starkly different context in many ways to the countries that have been at the center of the dialogue on gender equality and education. As the most populous region in the world, the higher education of women in Asia has the potential to transform the global landscape and influence the trajectory of our collective future. Though it is generally accepted that gender inequality in education hinders progress in a variety of ways, the focus tends to be on primary and secondary educational attainment. The policies targeting primary education and even secondary education for girls have been tremendously successful in Asia, with many countries achieving almost complete coverage at the primary level, and significant improvement in the rates of secondary school enrolment. Women's enrollment in secondary school has increased dramatically throughout the region, and, in many countries, the traditional gender gap in secondary school enrollment is gradually disappearing. In South Korea, Thailand, and Hong Kong, secondary-school enrollment is nearly the same for both sexes, while in the Philippines it remains slightly higher for women.

However, higher education plays a unique role in creating socially engaged, civically active, and innovative individuals. As the President of Asia Society once remarked:

Whenever there is a public discussion about education and about women in Asia, the focus is generally on the need for basic literacy: that women should be able to read, write and count. It is fundamental to their wellbeing. Studies have shown that these basic skills have been instrumental in greater economic empowerment, political participation and social engagement of women at even the lower level of societies. While the value of this basic education is undeniable and it is also badly needed, one might argue that... if women are to take more leadership roles in all sections and segments of the society, it goes without saying that women must be prepared to embrace the challenges of leadership in the 21 st century. Seen 
from this perspective, perhaps the right question is: Can we afford not to pay attention to higher education for women in Asia? ${ }^{1}$

Neoliberal arguments have emphasized the economic returns on investments in women's participation in higher education, while others stress that higher education is a human right and is essential for the creation of a moral and progressive society, as it enables an ongoing participation in a "life of the mind." The benefits at a social level are also apparent in improved productivity and greater participation in the cultural and political life of a community.

What are the unique opportunities available to women accessing higher education in Asia, the home to some of the world's biggest economies and most rapidly developing nations? What are the obstacles female students face in unlocking their own potential? How can policies, institutions, and individuals contribute toward a more equitable education system for all, regardless of gender, race, or class? In this chapter, we address these and other questions, using the Asian context as the frame for discussion. We begin by examining recent trends and ongoing challenges for women's higher education in Asia, and then focus on the role of single-sex institutions and the case of Asian University for Women. Finally, we identify opportunities for progress and offer recommendations moving forward.

\section{Trends and Challenges}

In a rapidly changing international economy, the strong commitment of developing countries to focus principally on primary education, sometimes at the cost of higher education, has been increasingly coming under scrutiny. Today's so-called global "knowledge revolution" represents a shift in international economic systems, whereby production processes are becoming increasingly technical and science-based, increasing the importance of higher education. Much of the analyses have missed many important social and economic effects of higher education that are critical to long-term economic growth and development. To the extent that the value of these benefits outweighs the costs, higher education represents a sound investment.

\footnotetext{
${ }^{1}$ Vishakha N. Desai, quoted in Asian University for Women Plan of Operation (Chittagong: AUW, 2005), 20. Accessed July 3, 2019, from http://asian-university.org/wpcontent/uploads/2018/08/AUW-Plan-of-Operations.pdf.
} 
Women today have greater access to higher education and degreegranting institutions today than at any other point in history. However, it is important to examine the reasons for this development as well as analyze the barriers that continue to keep higher education out of reach for many women. Furthermore, once women have crossed the threshold of higher education institutions, certain inequalities widen and gender norms are reinforced, even at single-sex universities. Finally, upon graduation, women are at a severe disadvantage when it comes to seeking employment. The trend of increasing privatization has the potential to address some of these issues, but only if effectively regulated.

\section{Growing Demand}

When praising the statistics showing women's increasing enrolment in higher education, many institutions and nations seem to be congratulating themselves on a job well done. While this trend is certainly to be celebrated, too rarely is the decision of women opting to pursue higher education emphasized. In this section, we address the question of why women are increasingly choosing to attend university. Gary Becker, William Hubbard, and Kevin Murphy create a model of the market for college graduates in order to analyze the costs and benefits of higher education. ${ }^{2}$ They conclude that while the benefits of attending college are no higher for women than for men, the differences in total cost can account for women overtaking men in college enrolments. Women have overall higher non-cognitive skills (such as self-motivation, self-discipline, and organization) than men, decreasing their total cost in continuing their education. Despite the fact that the authors claim to explain the global phenomenon of increased female representation in higher education, much of their evidence comes from data collected in the United States. Their evidence from other countries, when it comes to their key finding that women have higher non-cognitive abilities than men and thus a lower overall cost of entering higher education, stems from PISA test results, which do not include any South Asian countries. This kind of gap is all too common, and may lead to bias in supposedly unbiased data.

On the other hand, Mitra Shavarini approached this question by interviewing female students and faculty members in Iran about why they

\footnotetext{
${ }^{2}$ Becker, Hubbard, and Murphy, "Explaining the Worldwide Boom in Higher Education of Women," Journal of Human Capital 4, no. 3 (2010): 203-241.
} 
wanted to attend university and what they gained from it. ${ }^{3}$ She found four common themes: first, many viewed university as an escape from a controlling family environment or as a means to delay marriage. Second, students anticipated that a strong educational background could help them find a more suitable (higher class) husband. Third, women saw higher education as a means to raise their social status and sense of self-worth, and fourth, most believed a degree could offer them increased economic independence. These statements show that a shift in higher education toward increasing female enrolments is a result of women claiming agency over their education and their future. Instead of praising any particular institution or policy measure for the increase in women in higher education, it is important to recognize the women themselves who are putting in the work toward receiving their degrees. The reasons they give indicate that higher education offers them independence and a path toward success in a variety of ways. Though Becker, Hubbard, and Murphy also identified some similar factors in their description of the benefits of higher education for women, ${ }^{4}$ the idea of university as an escape from a restrictive family environment or an unwanted marriage is not addressed, potentially because of the American-centric focus of their study. In more conservative societies in Asia, this issue can be a more significant factor for women deciding whether to pursue higher education.

It is important to note here another difference from the American perspective. In Asia, education is often regarded as the primary path to economic success. ${ }^{5}$ Though there remain differences in how much families invest in sons as opposed to daughters, on all levels of the socioeconomic ladder, people are likely to see education for their children as the main way to improve their situation. This attitude is most evident in East Asia. On the other hand, in the United States, it can be argued that a focus on education is concentrated in families where the parents have strong educational backgrounds. The Coleman Report famously showed that family background is a greater determinant of educational outcomes than school

\footnotetext{
${ }^{3}$ Shavarini, "The Feminisation of Iranian Higher Education," International Review of Education 51, no. 4 (2005): 329-347.

${ }^{4}$ Becker, Hubbard, and Murphy, "Explaining the Worldwide Boom in Higher Education of Women."

${ }^{5}$ Melinda DP Bandalaria, "Open and Distance eLearning in Asia: Country Initiatives and Institutional Cooperation for the Transformation of Higher Education in the Region," Journal of Learning for Development 5, no. 2 (2018): 116-132.
} 
quality in the United States. However, later studies found that this effect is often the opposite in developing countries. ${ }^{6}$ Because families strongly prioritize education across the board in Asia, school quality can have a more significant impact than one's parents' educational attainment.

\section{Limitations to Women's Access}

A variety of barriers, from decisions on the familial level to national policies, continue to exist and reinforce one another to limit women's access to higher education. Though women's participation in higher education is increasing, a number of Asian nations have yet to fully close the gender gap. Furthermore, in many countries, the overall rates of enrolment in higher education are still so low that even if women were to attend university at the same rates as men, the vast majority of women would still be excluded. Finally, in many cases, women in higher education represent a narrow section of women in a country. Acknowledging that the progress toward gender equity in higher education favors some women and while excluding others is an important step toward creating more inclusive institutions and societies. When mentioning Asia in a United States-or Eurocentric discussion, many people point to religious and cultural conservatism as the reason for persistent gender inequalities in the region. While these are significant factors, they do not tell the whole story and often serve to reinforce false stereotypes about inherent sexism in a particular religion or culture. It is important to acknowledge how colonialism, particularly in South Asia, has shaped today's gender landscape in the region.

Women in Asia are not a homogenous group. Gender and class often interact to impede access to education. When there is a shortage of resources, women and girls often feel the negative impacts more strongly than men and boys. Many countries in Asia are lower-income, and thus offer less state support for higher education than their resource-rich counterparts. This increases the burden on families and students to pay for their education. In some countries, girls' education is seen as a less worthwhile investment than that of boys in part because they contribute more household labor from a younger age than boys. If they continue their

\footnotetext{
${ }^{6}$ Claudia Buchmann and Emily Hannum, "Education and Stratification in Developing Countries: A Review of Theories and Research," Annual Review of Sociology 27 (2001): 77-102.
} 
education, the family would not only need to spend money on school fees and related costs, but would also lose a significant source of labor. Many girls are expected to marry and focus on raising children rather than enter the workforce, so some families view their education, especially education beyond secondary school, as a sunk cost. However, this gender disparity in familial investment is much less pronounced in certain countries, particularly East Asian nations, Sri Lanka, the Philippines, and Thailand. ${ }^{7}$ Many parents see the education of their children as a path toward social mobility and have equal aspirations for their sons and daughters.

Another barrier on the familial level is an unwillingness to send girls and women far from home in order to further their education. This limitation can be found in both wealthy and poorer families, and is often caused by concerns for daughters' safety and security. If the only accessible institution of higher education is far from home, women are less likely to continue their education. Many families and communities also prefer gender-segregated education, which further limits the options female students have available to them. Moreover, women-only schools and universities often receive less funding and resources than their all-male or co-ed counterparts. This is one way in which the allocation of limited resources, the influence of traditional gender norms, and location interact to prevent women's attainment of higher education.

Women in Asia also face systemic and structural barriers to higher education. Certain national policies, even those intended to increase diversity, can end up limiting women's access. Rohini Sahni and Kalyan Shankar examine Indian policies in particular, and find that the structure of the quota system for public universities sometimes results in decreased enrolment opportunities for women. ${ }^{8}$ They also emphasize that educational development does not always amount to increased female inclusiveness, and note that within India, women's access to higher education varies widely based on location and caste. Certain regions have far more female students than others, and most women attending universities are from urban areas. Even though the overall gains in women's educational attainment since independence are encouraging, when examined more closely, it is unclear whether this growth can be sustained, mainly because of

\footnotetext{
${ }^{7}$ Swarna Jayaweera, "Gender and Access to Education in Asia," International Review of 33, no. 1 (1987): 455-466.

${ }^{8}$ Sahni and Shankar, "Girls' Higher Education in India on the Road to Inclusiveness: On Track but Heading Where?," Higher Education 63, no. 2 (2012): 237-256.
} 
these intersecting disparities. Adapting national and regional level policies to more clearly address the exclusion of certain groups of women and expanding the higher education system overall would be one move in the right direction, but would need to coincide with grassroots level reforms in order to be effective.

However, developing countries face their own barriers to reforms that might lead to greater gender equality. Buchmann and Hannum describe a few of the challenges faced by some governments in developing countries, such as a lack of resources, peripheral status in the world system, and uncertain legitimacy. ${ }^{9}$ These issues make creating and implementing policies difficult. For example, Pakistan has one of the widest gender gaps in Asia. ${ }^{10}$ The laws that are in place to empower women and shrink this gap are often ineffective because of entrenched patriarchal norms and the government's inability to enforce its laws. Many women are not even aware they have rights, yet they still find a way to pursue their education. The barriers they face come from all sectors of society and even sometimes their own families, and so it is imperative that reforms occur in all sectors as well. Government policies can be difficult to implement if the society rejects their intended purpose.

\section{Quality Concerns and Privatization}

A huge trend in higher education in Asia is increasing privatization, which in many cases also limits the educational opportunities available to women. Asia is now the largest provider of private higher education by enrolment, and is home to the largest distance learning institution in the world - the Indira Gandhi National Open University in India. Because of the increasing demand for higher education that public funds are unable to meet, the private sector has stepped in. However, private higher education in Asia has shifted toward a focus on industry and profits. Private institutions are often less concerned with facilitating diversity and inclusion than they are with recruiting students who will pay high tuition fees and gearing those students toward the corporate sector. There must be

\footnotetext{
${ }^{9}$ Buchmann and Hannum, "Education and Stratification in Developing Countries."

${ }^{10}$ Malik, Samina, and Kathy Courtney. "Higher Education and Women's Empowerment in Pakistan," Gender and Education 23, no. 1 (2011): 29-45.
} 
a balance in government policy that allows the private sector to flourish in order to meet the demand for higher education and regulates it enough to ensure certain standards of quality and equality are met. Even so, some argue that the private sector cannot meet enrolment demand as effectively as public institutions. Tilak notes that government spending is much more highly correlated with enrolment rates than private expenditure. ${ }^{11}$ When governments pull funding, the resulting gap is not always met with increases in spending by private entities. Tilak argues that investment by the state in higher education is indispensable and irreplaceable. Furthermore, the private sector's focus on certain subjects (generally engineering, information technology, and commerce) at the expense of others (often the arts, humanities, and social sciences) can limit the innovative and creative growth of a field and delay progress. Moreover, the subjects most commonly promoted by private institutions are those that women are often discouraged from pursuing, further limiting women's educational opportunities.

However, private institutions can also expand women's options by expanding the overall educational system. Certain private providers of higher education are aimed at particular minority groups or are singlesex. Leleh Jamshidi et al. argue that private entities can address "differentiated demand" - demand for a specific form or focus of higher education - more quickly than public institutions. ${ }^{12}$ Thus, increased demand for gender-segregated higher education could be met by private, singlesex institutions that allow women who may not otherwise have had any options to continue their education. But the authors also emphasize that coordination between the state and the private sector is essential for success. Private institutions are not necessarily a solution to gender disparities, but they can be a tool to advance women's educational attainment.

\section{Inequality in Experience}

Access to higher education is just one piece of the puzzle when it comes to women's overall experiences. Once they enter these institutions, whether

${ }^{11}$ Jandhyala B. G. Tilak, "Higher Education in South Asia: Crisis and Challenges," Social Scientist 43, nos. 1/2 (2015): 43-59.

${ }^{12}$ Laleh Jamshidi, Hamidreza Arasteh, Abdolrahim Naveh Ebrahim, Hassanreza Zeinabadi, and Palle Damkjer Rasmussen, "Developmental Patterns of Privatization in Higher Education: A Comparative Study," Higher Education 64, no. 6 (2012): 789-803. 
they are public, private, single-sex, or co-ed, women are faced with an entirely new set of challenges that reveal less encouraging statistics in terms of gender equality. As previously mentioned, women continue to be overrepresented in certain disciplines and underrepresented in others. Sometimes known as gender tracking, this can result from a variety of outside factors, ranging from societal constructs about which fields are seen as more "feminine" or "masculine" to outright hostility in male-dominated classrooms and labs. Meenakshi Gautum discusses this issue with a focus on India. ${ }^{13}$ She finds that fathers generally play a key role in decisions about which subject to pursue, especially in middle class and upper middle class families in urban areas. Students from lower class backgrounds were more likely to make this decision on their own, mainly because their families had little familiarity with the higher education system and which subjects might be considered more employable or prestigious. Gautum found that fathers influenced the decision-making process for both sons and daughters. However, the more prestigious subjects were generally the automatic choice for boys, while the subject choice for girls was more dependent on their perceived ability to work hard. Aside from family influence, there is often a chilly atmosphere for those women who do attempt to enter male-dominated fields in technology, engineering, and business. ${ }^{14}$ Overall, there are significant disparities across Asia and worldwide in terms of the disciplines men and women study, and this gender gap has yet to improve as much as the enrolment gap has. ${ }^{15}$

The everyday experience of attending an institution of higher education is also different for women and men. Universities, even those that are single sex, often contribute to reinforcing gender roles and norms. Certain textbooks and teaching materials erase the contributions women have made in various fields and society in general, and instructors (regardless of gender) often show bias toward male students. ${ }^{16}$ Female students are also more likely to be victims of sexual harassment and assault than

${ }^{13}$ Gautam, "Gender, Subject Choice and Higher Education in India: Exploring 'Choices' and 'Constraints' of Women Students," Contemporary Education Dialogue 12, no. 1 (2015): 31-58.

${ }^{14}$ Kristen A. Renn, "Roles of Women's Higher Education Institutions in International Contexts," Higher Education 64, no. 2 (2012): 177-191.

15 Patricia Licuanan, “The Challenge of Women's Higher Education in Asia," International Higher Education 37 (2015): 16-18.

${ }^{16}$ Malik and Courtney, "Higher Education and Women's Empowerment in Pakistan." 
their male peers. Furthermore, a lack of women in the administration and on the faculty of higher education institutions leads to a lack of institutional support, mentorship, and leadership opportunities for women. While some of these issues are mitigated at single-sex institutions, they are by no means eliminated. The education system often reinforces gender inequalities instead of diminishing or eliminating them. This issue is part of the reason gender inequality in employment outcomes persists so strongly despite the huge gains in gender parity in terms of enrolments.

\section{Inequality in Outcomes}

Female graduates face different employment opportunities than male degree holders and furthering their education can ironically even lower their chances of finding work. In some countries, such as India, women with more education are less likely to be employed than their less educated counterparts. ${ }^{17}$ Women in India who have completed higher education have a slight boost in employment rates over those with only a secondary level education, but their rates of employment are still lower than women with a primary school education or no education. This apparent paradox is the result of a variety of factors. Education offers benefits in the marriage market, and so higher levels of education might allow some women to marry into higher income families. The reinforcement of gender roles in society and the education system could be a part of why they choose not to work. Indeed, when accounting for other family income, the U-shaped effect that arises when mapping education level to labor force participation is less strong, but still present, so this explanation does not explain the entire picture. Another major reason is that there are simply no appropriate jobs for women with a moderate level of education. Women with the least education are generally participating in wage labor or working on family farms, and the expected negative correlation between these forms of labor and education level is present. However, there are simply too few salaried jobs available for the women that enter the job market with moderate to high qualifications.

Women who have completed higher education do not have the same opportunities and advantages available to them as men. In order for the development of a country to utilize the human capital of half of their

${ }^{17}$ Chatterjee, Esha, Sonalde Desai, and Reeve Vanneman, "Indian Paradox: Rising Education, Declining Women's Employment,” Demographic Research 38 (2018): 855-878. 
citizens, governments and societies must view female graduates as an irreplaceable resource. Discrimination in the job market and the workplace as well as societal expectations about what roles women should play have significant detrimental impacts on the progress of a country. When women attain degrees at similar rates to men but hold far fewer tenure track or higher level administrative positions in academia, a cycle of inequality is perpetuated. Arguably the biggest challenge with respect to higher education for women in Asia is no longer gender parity in terms of access but gender equality throughout the educational process and in the outcomes. If universities continue to mirror and propagate the gender stereotypes and biases present in society at large, there will be no progress on this front.

\section{Emergence of Single-Sex Institutions}

One distinctive feature of higher education in Asia is the rapid increase in women's only universities, especially considering their ongoing decline in the United States and many other western countries. Single-sex institutions theoretically provide solutions to many of the barriers discussed up to this point. They expand access for women whose families or circumstances would not allow them to attend a co-educational institution, and they can break down barriers to certain subject areas that are often hostile environments for women. Women's institutions often generally have an implicit or explicit focus on female empowerment, whether through a gender studies program or simply ongoing dialogue about women's issues and women's rights. They are able to provide an environment conducive to growing strong leaders, developing self-confidence and self-esteem, and preparing graduates to take on leadership roles as they enter the workforce. The results of these differences are tangible; numerous studies have shown women who attend single-sex institutions are higher achievers, and leave their mark in a wider range of fields including science, the arts, humanities, and business.

However, women's institutions also often face financial constraints as well as quality concerns. And despite being symbols of the advancement of women's status in society, they also often perpetuate traditional gender norms. ${ }^{18}$ Leadership and faculty positions at single-sex institutions are

${ }^{18}$ Renn, "Roles of Women's Higher Education Institutions in International Contexts." 
still mostly filled by men, and social stratification along the lines of race, ethnicity, and class can also be reproduced at women's universities. It is essential that these institutions prioritize inclusion and tolerance in order to fulfill the mission of women's empowerment many were founded on.

\section{Gender on the Agenda: The Case of Asian University for Women}

Against the well-rehearsed advantages of women's colleges and rooted in historic traditions for promoting empowerment and development of leadership skills among women, Asian University for Women (AUW) was established in 2008 in Chittagong, Bangladesh, with the intention to provide women drawn from diverse social, economic and language backgrounds with opportunities become critical thinkers and ethical leaders in their home communities. It was also based on the assumption that a single-sex institution, when done right, will not duplicate the assumptions and practices of the dominant culture that would exclude women from full participation in certain professions and certain aspects of societal life. Furthermore, a World Bank report that investigated barriers to women's higher education concluded that in countries like India, Pakistan, Nepal, Bangladesh, and many sub-Saharan African countries, the creation of single-sex institutions was both necessary and justified in addressing the disparity in women's higher education in these settings. The establishment of AUW was not only to provide quality education to women who might otherwise be unable to attend university due to cultural pressures, but also to provide a setting in which these young women can reflect on their individual and collective roles in their societies, and on how those roles can be recast for the benefit of all.

With more than 800 students enrolled on campus, AUW continually seeks to extend its outreach to recruit young women from the most underserved communities. AUW recruits talented and engaged students, regardless of their background or ability to pay tuition. In this way, AUW provides promising young women with the opportunities they deserve, and aims to establish a new talent pool of future leaders from all walks of life. Drawing from seventeen countries across Asia and the Middle East, AUW's recruitment efforts extend to local madrassas, hill tribes, ready-made garments factories, refugee communities, ethnic minorities in Afghanistan and Myanmar, daughters of microfinance borrowers and workers on the tea estates of Assam, Sri Lanka, and Sylhet. Systematic engagement with local schools, families, and NGOs helps AUW to 
access potential students and overcome any cultural and social barriers that young women from these underprivileged groups face.

Not all students arriving at AUW have received rigorous secondary schooling or English language training. Many have experienced poverty, displacement, and political instability and are in need of intensive remedial education. Pre-collegiate programs at AUW are founded upon the principle that circumstance is not an indicator of potential. AUW established Pathways for Promise in January 2016 as a tailored preparatory program with the ability to sufficiently equip any woman for undergraduate education. In Pathways, women who have not previously had access to high-quality English-language or mathematics training receive an additional year of pre-university preparation in advance of the oneyear Access Academy and then three-year Undergraduate Program. Access Academy is a flagship year of pre-collegiate courses at AUW with ten years' experience, focusing on English communication skills, critical thinking, problem-solving, and strategies for lifelong learning. The program is designed to help students overcome prior deficits in their educational background and prepare for success in AUW's Undergraduate Program.

In line with its mission, AUW's curriculum is interdisciplinary and cross-cultural in nature, and its faculty and staff engage students in applying theoretical knowledge to real-world problems. While its liberal learning curriculum draws in part upon a western liberal arts tradition, the curriculum is based on significant Asian content and the University's programs encourage students to apply the analytical tools they acquire to regional problems. Rather than separating education from professional training, the curriculum takes the best of the liberal arts tradition and integrates it with professional training for careers and leadership.

It was our founders' hope that a strong liberal education such as this would lay the foundation for a life of learning and thinking critically in a rapidly changing world. This is particularly important in today's knowledge-based economy, where technologies and production processes are constantly being modified and the ability for continuous learning and relearning is critical for remaining at the forefront of the business and scientific world. AUW students are high achievers and ready to take on leadership roles following the completion of their studies. Graduates are employed in a range of organizations including non-profit, research institutions, private companies, schools, non-governmental organizations, and 
government departments. Many go to graduate schools in top universities around the world and some even start their own ventures. Diversity is AUW's strength and priority, providing a varied and distinct community comprised of students, faculty and staff members from a wide range of economic, cultural, locational - rural/urban, ethnic, and religious backgrounds.

\section{Opportunities AND ReCOMMENDATIONS}

Clearly, efficient investment in women's higher education can bring huge returns, but these returns will not materialize if the gaps in women's experiences at university and outcomes post-graduation are not addressed. Graduate unemployment is sometimes used as a reason to limit public funding for higher education, but this issue is often more to do with a lack of robust quality standards rather than education not being a worthwhile investment. ${ }^{19}$ Education is unequivocally a public good and should be treated as such. The scarcity of high-level talent in developing countries coincides with a time of unprecedented demands for such capacity. Creating diverse and inclusive institutions of higher education will allow entire nations to reap the benefits of previously untapped potential, and should be a priority for all. This section will address specific reforms that can be made at the institutional, governmental, and individual levels to work toward this goal.

\section{Government Level Reforms}

As many governments of Asian countries are resource-poor, it is not feasible for them to subsidize higher education for everyone. The demand far outstrips the state's ability to supply. However, there are many steps and policies that could be taken to promote equality and inclusion. One essential point is creating policies to both support and regulate private institutions of higher education. The private sector can effectively complement public institutions in order to provide access to more students. To be sure, privatization has been accelerating in Asia regardless of government action. However, countries such as Malaysia and Indonesia have implemented policies that encourage the growth of privatization while

${ }^{19}$ Tilak, "Higher Education in South Asia." 
also ensuring certain academic standards are met. ${ }^{20}$ Quality assurance mechanisms can come in a variety of forms, and are possibly one of the most important roles a state can and should play in higher education. Again, returns on investments in higher education will not manifest if the educational institutions are lacking in quality. National-level policies can also successfully encourage diversity through affirmative action or quota systems. While these can be effective tools, they do not always have the intended effects. It is important to ensure, when formulating such policies, that they will not further disadvantage one underrepresented group in favor of another, but rather offer more opportunities to all underrepresented and vulnerable groups. Providing families, particularly those of a lower socioeconomic status, incentives to educate girls is also recommended. When costs of education are eliminated, children are much more likely to attend school, and for families who are less willing to spend money on their daughters than their sons, this kind of measure can make a huge difference in gender equity.

\section{Institutional Level Reforms}

Higher education institutions themselves have arguably the most influence over student access, experience, and outcome. Besides ensuring an academically rigorous and comprehensive curriculum, institutions should work to dismantle harmful systems of stratification that are too often reinforced within their halls. Active recruitment of female leadership and faculty members is an essential step toward creating a more equal experience for male and female students. This move will allow female students to find mentors that understand the challenges they face and can prioritize their distinctive needs. Representation is an essential aspect of fostering diversity. Cross-institutional collaboration can be an effective tool in this regard. Whether co-educational or single-sex, institutions of higher education can benefit from working together to solve system-wide problems.

In order to recruit from a broader pool of students, universities can work with each other (co-educational institutions in particular can learn from single-sex institutions) to develop concrete strategies for overcoming social and cultural barriers to women pursuing higher education. Reaching out to local organizations and secondary schools, emphasizing the

${ }^{20}$ Jamshidi et al., "Developmental Patterns of Privatization in Higher Education." 
safety and security of the campus environment, as well as the benefits of higher education to the family and community, is one method. Sending female representatives of the university to talk about their experiences can alleviate the concerns of those uncertain about attending a majority male institution. Providing scholarships aimed at recruiting female students will help overcome financial barriers for prospective students, put in place by families who are hesitant to spend money on a daughter's education. Institutions should also be wary of gender tracking, and promote women's participation in traditionally male-dominated fields. One component of this effort should be to ensure that teaching materials do not ignore the contributions made by women in their fields. The "hard sciences" cannot isolate themselves from social issues. All students, male and female, should be aware of the pervasiveness of gender discrimination and the all too common erasure of women's achievements. Encouraging faculty members to address these topics in their courses, whether in the humanities or the sciences, will go far in making female students feel heard and supported. Campus climate is another key factor of women's experiences in higher education. Strong policies and procedures for handling cases of sexual harassment and assault, open dialogue promoting women's empowerment and rights, and having various support systems and resources in place can enable women to thrive in a university setting. Comprehensive mental health support is a vital aspect of success in university, and robust processes for addressing student complaints are essential in building trust and community. Ensuring women have opportunities to develop their leadership skills is also vital. In co-ed institutions, leadership positions are overwhelmingly more male than the makeup of the student body. This issue goes hand in hand with ensuring female students have female mentors and leaders in the university administration that can guide them toward leadership opportunities. This helps them to build connections and skills that will improve their employment outcomes and allow them to use their education to help themselves, their families, and their communities.

Furthermore, diversity and access should be explicitly prioritized by everyone from student leaders to the administration. It needs to be clear that diversity and inclusion are core values of the institution and not simply a matter of numbers or quotas. Institutional leadership must vocally 
denounce intolerance and discrimination in all forms. Implementing trainings for faculty and staff focused on creating a university-wide community that prioritizes breaking down patriarchal norms and other harmful societal structures is another way to create an inclusive space. These trainings should help faculty and staff become more aware of classroom dynamics that allow male students to dominate as well as other challenges female students face so that they can more effectively support them. These changes cannot be put in place overnight, but if the leaders of a university prioritize female students and listen to their needs and concerns, they have already taken a significant step toward creating a more equal system of higher education and unlocking the potential of their female students.

\section{CONCLUSION}

Some have already dubbed the twenty-first century the Asian Century. However, this emerging region needs a generation of new innovators in order to truly address its long-standing social, political, and economic issues. Every member of society has a part to play in promoting progress and development through eliminating gender disparities. While it is important to recognize the interrelatedness of the challenges facing women's higher education in Asia, by the same token, widespread change can be achieved through relatively small shifts at the grassroots level. Everywhere in Asia there are examples of great tides of change. New roles are being demanded of countries, communities, and citizens. Women in Asia have been prominent at the highest levels - India, Pakistan, Bangladesh, Sri Lanka, Indonesia, Philippines, and now Myanmar all have had women as heads of state or government. Today, Asian women from all walks of life are gaining opportunities to succeed in these societies and to capture their rightful places as leaders, experts, and visionaries who can realize their full potential. Having been historically excluded from academia, women in Asia are claiming their space in higher education. They represent the future of development and innovation in the region. 


\section{BIBLIOGRAPHY}

Asian University for Women. Asian University for Women Plan of Operation. Chittagong: AUW, 2005. Accessed July 3, 2019, from http://asian-university. org/wp-content/uploads/2018/08/AUW-Plan-of-Operations.pdf.

Bandalaria, Melinda DP. "Open and Distance eLearning in Asia: Country Initiatives and Institutional Cooperation for the Transformation of Higher Education in the Region." Journal of Learning for Development 5, no. 2 (2018): 116-132.

Becker, Gary S., William H. J. Hubbard, and Kevin M. Murphy. "Explaining the Worldwide Boom in Higher Education of Women." Journal of Human Capital 4, no. 3 (2010): 203-241.

Buchmann, Claudia, and Emily Hannum. "Education and Stratification in Developing Countries: A Review of Theories and Research." Annual Review of Sociology 27 (2001): 77-102.

Chatterjee, Esha, Sonalde Desai, and Reeve Vanneman. "Indian Paradox: Rising Education, Declining Women's Employment.” Demographic Research 38 (2018): 855-878.

Gautam, Meenakshi. "Gender, Subject Choice and Higher Education in India: Exploring 'Choices' and 'Constraints' of Women Students." Contemporary Education Dialogue 12, no. 1 (2015): 31-58.

Jamshidi, Laleh, Hamidreza Arasteh, Abdolrahim Naveh Ebrahim, Hassanreza Zeinabadi, and Palle Damkjær Rasmussen. "Developmental Patterns of Privatization in Higher Education: A Comparative Study." Higher Education 64, no. 6 (2012): 789-803.

Jayaweera, Swarna. "Gender and Access to Education in Asia." International Review of Education 33, no. 1 (1987): 455-466.

Licuanan, Patricia. "The Challenge of Women's Higher Education in Asia." International Higher Education 37 (2015): 16-18.

Malik, Samina, and Kathy Courtney. "Higher Education and Women's Empowerment in Pakistan." Gender and Education 23, no. l (2011): 29-45.

Renn, Kristen A. "Roles of Women's Higher Education Institutions in International Contexts." Higher Education 64, no. 2 (2012): 177-191.

Sahni, Rohini, and V. Kalyan Shankar. "Girls' Higher Education in India on the Road to Inclusiveness: On Track but Heading Where?" Higher Education 63, no. 2 (2012): 237-256.

Shavarini, Mitra K. "The Feminisation of Iranian Higher Education." International Review of Education 51, no. 4 (2005): 329-347.

Tilak, Jandhyala B. G. "Higher Education in South Asia: Crisis and Challenges." Social Scientist 43, nos. 1/2 (2015): 43-59. 
Open Access This chapter is licensed under the terms of the Creative Commons Attribution 4.0 International License (http://creativecommons.org/licenses/ by $/ 4.0 /$ ), which permits use, sharing, adaptation, distribution and reproduction in any medium or format, as long as you give appropriate credit to the original author(s) and the source, provide a link to the Creative Commons license and indicate if changes were made.

The images or other third party material in this chapter are included in the chapter's Creative Commons license, unless indicated otherwise in a credit line to the material. If material is not included in the chapter's Creative Commons license and your intended use is not permitted by statutory regulation or exceeds the permitted use, you will need to obtain permission directly from the copyright holder.

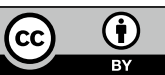

